\title{
CONSUMPTION OF SWEETENED SOFT DRINKS AND ENERGY DRINKS IN ADOLESCENTS IN SLOVAKIA: IMPLICATIONS FOR PAEDIATRIC NURSING
}

\author{
Martina Bašková1, Tibor Baška ${ }^{2}$, Jana Holubčíková ${ }^{3}$ \\ ${ }^{l}$ Department of Midwifery, Jessenius Faculty of Medicine in Martin, Comenius University in Bratislava, Slovakia \\ ${ }^{2}$ Department of Public Health, Jessenius Faculty of Medicine in Martin, Comenius University in Bratislava, Slovakia \\ ${ }^{3}$ Department of Health Psychology, Faculty of Medicine, Pavol Jozef Šafárik University in Košice, Košice, Slovakia
}

Received January 15, 2016; Accepted February 21, 2016. Copyright: This is an open access article distributed under the terms of the Creative Commons Attribution International License (CC BY). http://creativecommons.org/licenses/by/4.0/

\begin{abstract}
Aim: The study analyzed the consumption of sweetened soft drinks and energy drinks as well as attitudes towards their consumption. Design: Health Behaviour in School-aged Children (HBSC) is a cross-sectional school-based study focused on the target group of 11-, 13- and 15-year-old adolescents. It employs a universal, internationally standardized questionnaire. Methods: The study analyzes results of the HBSC survey carried out in Slovakia in 2014. A total of 10,179 schoolchildren from grades 5 through 9 participated (a response rate of 78.8\%). Gender and age differences were analyzed in 11-, 13- and 15year-old respondents. Results: The consumption of soft drinks varied from 16.9\% (11-year-old girls) to $29.0 \%$ (15-year-old boys). More than 8 in 10 respondents accepted the consumption of soft drinks. As much as $34.4 \%$ of boys and $18.8 \%$ of girls aged 15 years reported the use of energy drinks at least weekly, with boys showing higher rates than girls in all age groups and the rates increasing with age. Conclusion: In Slovakia, consumption of sweetened soft drinks and energy drinks is widely popular and socially accepted among adolescents. There is a need for more effective interventions including adoption of appropriate legislative norms. Pediatric nursing plays an important role through outpatient primary as well as hospital care.
\end{abstract}

Keywords: HBSC, sweetened soft drinks, energy drinks, adolescents, pediatric nursing.

\section{Introduction}

Nutrition during adolescence requires maximum attention, not only with respect to the need for the optimal biological and energy value of a diet, but also because during this period, dietary habits develop and can be effectively positively modified from the perspective of the future life. When managing the nutrition of children and adolescents, attention should be paid to the development of appropriate dietary habits since these will remain throughout the life. This is important as the attitudes and habits are easier to modify in young children than in the older age groups.

Sweetened soft drinks pose a risk mainly by affecting the appropriate dietary intake in children and adolescents.

Corresponding author: Martina Bašková, Department of Midwifery, Jessenius Faculty of Medicine in Martin, Comenius University in Bratislava, Malá Hora 5, Martin, Slovakia; e-mail: Martina.Baskova@jfmed.uniba.sk
Their high content of carbohydrates in the form of mono- and disaccharides increases the level of glucose in the blood immediately after their consumption, leading to a feeling of satiety followed by increased insulin production (Simon, Mosher, 2007). However, simple saccharides are quickly metabolized and the released insulin subsequently causes hypoglycemia triggering the feeling of hunger and craving for sweets. Thus, a vicious circle develops, potentially leading to overweight and obesity. Moreover, regular consumption of sweetened soft drinks significantly contributes to tooth decay.

Consumption of energy drinks represents a specific problem. In recent years, an increase in their use by children and adolescents has been evidenced in most developed countries (Pomeranz et al., 2013; Alsunni, 2015). Therefore, their adverse effects and consequent impacts in these age groups are legitimate reasons for concern (Marczinski, Fillmore, 2014; Alsunni, 2015). Besides the high amounts of simple saccharides, energy drinks contain stimulants, mostly caffeine, causing both physiological and behavioral changes (Sanchis-Gomar et al., 2015). They affect particularly the cardiovascular and nervous systems 
(Salamon, 2011; Ali et al., 2015) and association with hyperactivity and loss of concentration in children has been reported (Schwartz et al., 2015). Their consumption is also related to substance abuse, increased frequency of injury due to high-risk behavior (Hamilton et al., 2013; Ali et al., 2015), as well as an increased risk of problematic alcohol use later in the life course (Miyake, Marmorstein, 2015).

Health Behaviour of School-aged Children (HBSC) is an international project of cross-sectional surveys monitoring health and health-related behavior in school children aged 11, 13 and 15 years. Currently, more than 40 countries participate, mostly from Europe. These studies analyze various aspects of health and health-related behavior in adolescents. The project is coordinated by the Child and Adolescent Health Research Unit (CAHRU) at the University of St Andrews, UK and the University of Bergen, Norway, together with the WHO Regional Office for Europe.

\section{Aim}

The aim was to analyze the consumption of sweetened soft drinks and energy drinks by school children as well as their attitudes towards the consumption of sweetened drinks in the HBSC survey carried out in Slovakia in the school year 2013/2014.

\section{Methods}

\section{Design}

The HBSC is an international school-based crosssectional study. Its standardized design allows the production of harmonized datasets suitable for crosscountry comparisons as well as identification of trends. The goals of the study are to monitor health and health-related behavior in thesocial context and to deepen understanding of the mechanisms influencing differences and changes in health and risk behavior of school children.

\section{Sample}

The sample is created in accordance with the structure of the educational system in a particular country and is stratified by regions and types of school to obtain representative data on 11-, 13- and 15 -year-old adolescents. The primary unit is a school class. The sample of schools was stratified by regions (eight administrative self-governing regions) and types of school (elementary schools including grades 1 through 9 and eight-year grammar schools including grades 6 through 13). A total of 151 larger and smaller elementary schools located in both rural and urban areas of all regions of Slovakia were randomly selected using a list of all eligible schools in the country obtained from the Slovak Institute of Information and Prognoses of Education. Of those, 130 schools agreed to participate (a response rate of $86.1 \%$ ). The data collection was carried out in the spring of 2014. Data were obtained from 10,179 adolescents from grades 5 through 9 of the schools (a response rate of $78.8 \%$ ). Only 11-, 13- and 15-yearold respondents were included in the analysis. (Table 1)

Table 1 Basic characteristics of analyzed samples obtained in a 2013/2014 HBSC survey in Slovakia

\begin{tabular}{lllll}
\hline & Mean age & $\begin{array}{l}\text { Boys } \\
(\mathbf{n})\end{array}$ & $\begin{array}{l}\text { Girls } \\
(\mathbf{n})\end{array}$ & $\begin{array}{l}\text { Total } \\
(\mathbf{n})\end{array}$ \\
\hline $\begin{array}{l}11 \text { year } \\
\text { olds }\end{array}$ & $\begin{array}{l}11.48 \\
(\mathrm{SD}=0.28)\end{array}$ & 776 & 758 & 1,534 \\
$\begin{array}{l}13 \text { year } \\
\text { olds }\end{array}$ & $\begin{array}{l}13.51 \\
(\mathrm{SD}=0.27)\end{array}$ & 1,035 & 112 & 2,162 \\
$\begin{array}{l}15 \text { year } \\
\text { olds }\end{array}$ & $\begin{array}{l}15.39 \\
(\mathrm{SD}=0.26)\end{array}$ & 813 & 736 & 1,549 \\
\hline SD- standard deviation & & &
\end{tabular}

\section{Data collection}

Data are collected in school classes by trained field administrators using an anonymous questionnaire. The HBSC questionnaire includes both mandatory modules of questions used in all participating countries and optional modules containing sets of questions based on specific needs of individual countries. The mandatory modules contain questions on demographic data, indicators of health and disorders, health-related behavior (dietary habits, dental hygiene, weight control, physical activity, and substance use), violence, school environment, family, peers and leisure time activities. The optional modules based on specific needs of individual countries extend the basic groups of questions included in the mandatory modules (Roberts et al., 2007).

Answers to the following questions were analyzed:

- "On how many days a week do you usually drink coke or other soft drinks that contain sugar?" The possible answers were "never", "less than once a week", "once a week", "2-4 daysa week", "5-6 days a week", "once a day, everyday", and "everyday more than once". The rates of respondents claiming to consume sweetened soft drinks at least once a day are presented.

- "In your opinion, what is the best way to characterize the attitudes of the majority (at least $51 \%$ ) of your schoolmates regarding drinking coke or other soft drinks that contain sugar?" The possible answers were "It is never OK", "It is OK to try it", "It is sometimes OK", and "It is OK to do it frequently". The rates of respondents 
identifying "It is OK to try it", "It is sometimes OK", or "It is OK to do it frequently" are presented. Only 13- and 15-year-old respondents answered this question.

- "Is it OK if your classmates drink coke or other soft drinks that contain sugar?" The possible answers were "It is never OK", "It is OK to try it", "It is sometimes OK", and "It is OK to do it frequently". The rates of respondents identifying "It is OK to try it", "it is sometimes OK", or "It is OK to do it frequently" are presented. Only 13and 15-year-old respondents answered this question.

- "In your opinion, how many of your classmates drink coke or other soft drinks that contain sugar?" The possible answers were "none of them", "few of them", "several of them", "most of them" and "all of them". The rates of respondents identifying "most of them" or "all of them" are presented. Only 13- and 15-year-old respondents answered this question.

- "How many days a week do you usually drink energy drinks such as Red Bull?" Possible answers were "never", "less than once a week", "once a week", "2-4 days a week", "5-6 days a week", "once a day, everyday" and "everyday more than once". The rates of respondents claiming to consume energy drinks more than once a week are presented.

\section{Data analysis}

Differences in the variables between girls and boys, as well as between age groups were evaluated by univariate logistic regression. The reference groups were girls (comparison between genders) and 15- year-old respondents (comparison between age groups). The differences were expressed as an odds ratio (OR) and 95\% confidence interval (CI 95\%). The odds ratio indicates how many times more probable the particular value of a variable is in the compared group than in the reference group. If the $\mathrm{OR}$ is greater than 1 , the probability is increased. If the OR is less than 1 , the probability is decreased. If the OR is equal to 1 , the probability is the same in both the compared group and the reference group. The confidence interval expresses the level of uncertainty.

\section{Results}

About one-quarter of respondents reported daily consumption of sweetened soft drinks. The highest and lowest prevalence rates were among 15-year-old boys (29\%) and 11-year-old girls (17\%), respectively. Gender differences were significant in only 11 year olds, with boys reporting daily consumption 1.4 times more frequently than girls. Eleven year olds reported daily consumption of soft drinks 0.6 or 0.7 times less frequently than 15 year olds. (Table 2) The other associations were not considered statistically significant since the confidence interval was greater than 1 .

More than $80 \%$ of respondents thought that most of their classmates drank sweetened soft drinks. Among 15 year olds, this view is less frequent in boys than in girls $(\mathrm{OR}=0.6)$. In girls, the prevalence increased with age, being less probable in 13 years olds than in 15 year olds $(\mathrm{OR}=0.7)$. (Table 3$)$

Table 2 Daily consumption of sweetened soft drinks

\begin{tabular}{llll} 
& $\begin{array}{l}\text { Boys } \\
\text { n }(\%)\end{array}$ & $\begin{array}{l}\text { Girls } \\
\text { n }(\%)\end{array}$ & $\begin{array}{l}\text { Boys vs. girls } \\
\text { OR (CI 95\%)* }\end{array}$ \\
\hline 11 year olds & $171(23.2)$ & $123(16.9)$ & $\mathbf{1 . 4}(\mathbf{1 . 1 5}-\mathbf{1 . 9 3})$ \\
13 year olds & $269(26.7)$ & $275(24.5)$ & $1.1(0.91-1.34)$ \\
15 year olds & $230(29.0)$ & $182(25.2)$ & $1.2(0.96-1.52)$ \\
11 year olds vs. 15 year olds OR (CI 95\%)* & $\mathbf{0 . 7}(\mathbf{0 . 5 9 - 0 . 9 3 )}$ & $\mathbf{0 . 6}(\mathbf{0 . 4 6 - 0 . 7 7 )}$ & \\
13 year olds vs. 15 year olds OR (CI 95\%)* & $0.8(0.72-1.10)$ & $0.9(0.78-1.21)$ & \\
\hline *statistically significant differences are printed in $)$ &
\end{tabular}

*statistically significant differences are printed in bold type, OR - odds ratio, CI-confidence interval

Table 3 An expressed view that most classmates drink sweetened soft drinks

\begin{tabular}{llll}
\hline & Boys & Girls & Boys vs. girls \\
& n $(\%)$ & n $(\%)$ & $0.8(0.65-1.10)$ \\
\hline 13 year olds & $853(86.3)$ & $957(88.2)$ & $0.8(0)$. \\
15 year olds & $694(86.4)$ & $664(91.5)$ & $\mathbf{0 . 6}(\mathbf{0 . 4 3}-\mathbf{0 . 8 3})$ \\
13 year olds vs. 15 year olds OR (CI 95\%)* & $1.0(0.76-1.3)$ & $\mathbf{0 . 7}(\mathbf{0 . 5 1}-\mathbf{0 . 5 6})$ & \\
\hline
\end{tabular}

*statistically significant differences are printed in bold type, OR - odds ratio, CI-confidence interval 
Similarly, an overwhelming majority of adolescents expressed a positive attitude towards consumption of soft drinks by their schoolmates. No significant differences were found between boys and girls or between 13 and 15 year olds, with the ORs being close to 1 . (Table 4)

Table 4 An expressed view that it is OK if schoolmates drink sweetened soft drinks

\begin{tabular}{llll}
\hline & $\begin{array}{l}\text { Boys } \\
\mathbf{n}(\boldsymbol{\%})\end{array}$ & $\begin{array}{l}\text { Girls } \\
\mathbf{n}(\boldsymbol{\%})\end{array}$ & $\begin{array}{l}\text { Boys vs. girls } \\
\text { OR (CI 95\%) }\end{array}$ \\
\hline 13 year olds & $866(87.6)$ & $972(89.7)$ & $0.8(0.62-1.07)$ \\
15 year olds & $695(86.7)$ & $653(89.8)$ & $0.7(0.54-1.01)$ \\
13 year olds vs. 15 year olds OR (CI 95\%) & $1.1(0.82-1.43)$ & $1.0(0.72-1.34)$ & \\
\hline OR - odds ratio, CI- confidence interval & & &
\end{tabular}

An overwhelming majority of respondents (more girls than boys) also shared the viewthat most of their schoolmates think that consuming sweetened soft drinks is OK. Among girls, the prevalence of the view increased with age. (Table 5)

Table 5 An expressed view that most schoolmates think that drinking of sweetened soft drinks is OK

\begin{tabular}{|c|c|c|c|}
\hline & $\begin{array}{l}\text { Boys } \\
\text { n (\%) }\end{array}$ & $\begin{array}{l}\text { Girls } \\
\text { n }(\%)\end{array}$ & $\begin{array}{l}\text { Boys vs. girls } \\
\text { OR (CI 95\%)* }\end{array}$ \\
\hline 13 year olds & $824(85.5)$ & $941(88.9)$ & $0.7(0.57-0.96)$ \\
\hline 15 year olds & $694(87.8)$ & $670(93.8)$ & $0.5(0.33-0.69)$ \\
\hline 13 year olds vs. 15 year olds OR (CI 95\%)* & $0.8(0.62-1.08)$ & $0.5(0.37-0.75)$ & \\
\hline
\end{tabular}

*statistically significant differences are printed in bold type, OR - odds ratio, CI-confidence interval

The prevalence of weekly or more consumption of energy drinks varied, ranging from 20\% (11 year olds) to $34 \%$ (15 year olds) among boys and from $6 \%$ (11 year olds) to $19 \%$ (15 year olds) among girls. Boys were considerably more likely to consume these drinks than girls; the probability was more than four times as high among 11 year olds and approximately twice as high in 13 and 15 year olds. The prevalence rates were clearly lower in younger age groups of both boys and girls. (Table 6)

Table 6 Weekly or more consumption of energy drinks

\begin{tabular}{llll}
\hline & Boys & Girls & Boys vs. girls \\
& $\mathbf{n}(\mathbf{\%})$ & n $(\boldsymbol{\%})$ & OR $(\mathbf{C I}$ 95\%)* \\
\hline 11 year olds & $142(19.5)$ & $40(5.5)$ & $\mathbf{4 . 1}(\mathbf{2 . 8 8}-\mathbf{6 . 0 1})$ \\
13 year olds & $278(27.7)$ & $181(16.3)$ & $\mathbf{1 . 9}(\mathbf{1 . 5 9 - 2 . 4 3 )}$ \\
15 year olds & $272(34.4)$ & $136(18.8)$ & $\mathbf{2 . 2}(\mathbf{1 . 7 8}-\mathbf{2 . 8 6})$ \\
11 year olds vs. 15 year olds OR (CI 95\%)* & $\mathbf{0 . 4}(\mathbf{0 . 3 6}-\mathbf{0 . 5 8})$ & $\mathbf{0 . 2}(\mathbf{0 . 1 7}-\mathbf{0 . 3 6})$ & \\
13 year olds vs 15 year olds OR (CI 95\%)* & $\mathbf{0 . 7}(\mathbf{0 . 5 9 - 0 . 8 9 )}$ & $0.8(0.65-1.07)$ & \\
\hline *statistically significant differences are printed in bold type, OR - odds ratio, CI-confidence interval & &
\end{tabular}

\section{Discussion}

The results of the HBSC study indicate that drinking of sweetened soft drinks is rather widespread among boys and girls in Slovakia and should be considered as a significant determinant of the development of obesity as well as tooth decay in this target population group. In this respect, the mild increase in their consumption with age should be a matter of concern.

When compared with other countries participating in a previous HBSC survey carried out in 2005/2006, Slovakia was among the European countries with the highest consumption rates (Currie et al., 2012). Given the fact that the situation in Slovakia has not changed considerably since the previous survey (Madarasova Geckova, Dankulincova, 2015), it may be assumed that the unfavorable position of Slovakia in the international context remains unchanged, suggesting the importance of more effective preventive interventions in that target group.

The HBSC study results summarizing the attitudes of respondents indicate a high level of social acceptance of soft drink consumption. An overwhelming majority of the respondents shared the opinion that their regular consumption is normal. Moreover, the 
prevalence of positive attitudes increased with age, particularly in girls. This may be due to the fact that, besides their being widely marketed in almost all media, their adverse effects do not occur immediately but become apparent only after a long period of time. Although soft drinks are a rich source of simple saccharides and greatly contribute to the overall energy intake, their association with overweight and obesity is usually not yet apparent during adolescence (Coppinger et al., 2013). Therefore, children underestimate their effect and are not aware of their role in the development of obesity.

Although consumption of energy drink is particularly a domain of boys, it cannot be underestimated in girls either. The marked increase in their consumption with age indicates their greater popularity in older age groups. The unfavorable situation in Slovakia is accented by comparing the results with those from other countries. For example, a study carried out in Canada showed that less than one-fifth of children aged 9 to 12 years reported consuming these drinks on a weekly basis (Hamilton et al., 2013; Reid et al., 2015). In Poland, a weekly use was reported by almost $10 \%$ of girls and $20 \%$ of boys (Nowak, Jasionowski, 2015). In this context, the frequency of consumption in Slovakia should be considered very high and the situation calls for appropriate attention because of potential impacts of the adverse effects of energy drinks. Such widespread use may be caused by intensive advertising campaigns focused particularly on youth. On the other hand, there is currently no legislation regulating the advertising and sales of energy drinks. Moreover, the mass media only rarely inform about the possible health impacts, resulting in inadequate awareness of the risks among the general public (Costa, Hayley, Miller, 2014).

As for the practical implications, the results of the analysis indicate the need to focus attention on sweetened drinks as a special issue within dietary recommendations. One possibility is the implementation of school-based programs already proven to be effective (Nanney et al., 2014). Pediatric nursing can contribute to such activities by providing consultations or supervision and organizing lectures and discussions with children in cooperation with schools.

Given the widespread use of energy drinks in Slovakia as compared with other countries, the general public should be better informed about them (Blankson et al., 2013), particularly within primary pediatric care, but also through school programs and employment of the mass media, internet and social networks. Besides, a discussion should be initiated on proposing legislation to regulate some ingredients (particularly caffeine), package labeling, and the distribution and sales of energy drinks (Pomeranz et al., 2013). Moreover, information on the use of energy drinks should be included in the patient's history taken in pediatric care as they may considerably contribute to the development of some cardiovascular or neurological disorders and behavioral changes and their use is associated with substance abuse (Ali et al., 2015).

Since the question on energy drinks was first included in the standard HBSC questionnaire only in the 2013/2014 survey, changes over time cannot be evaluated. Trends will be identified after the HBSC surveys to be performed in the future.

\section{Conclusion}

The study results showed that sweetened soft drinks and energy drinks are highly popular among adolescents. There is a need for more effective interventions, including adoption of necessary legislative norms. In these activities, pediatric nursing can play an important role through outpatient primary care as well as hospital care.

\section{Ethical aspects and conflict of interest}

The study was approved by the Ethics Committee of the Faculty of Medicine, P. J. Šafárik University in Košice. Parents were informed about the study via the school administration and could opt out if they disagreed with their child's participation. Participation in the study was fully voluntary and anonymous, with no explicit incentives provided for participation.

The authors declared no potential conflict of interests.

\section{Acknowledgements}

The study was partially supported by the Scientific Grant Agency of the Ministry of Education, Science, Research and Sport of the Slovak Republic and the Slovak Academy of Science, reg. no. 1/0895/14.

\section{Author contribution}

Conception and design (MB; TB), data analysis and interpretation $(\mathrm{JH} ; \mathrm{TB})$, drafting the manuscript (MB), critical revision of the manuscript (MB), finalization of the manuscript (MB).

\section{References}

Ali F, Rehman H, Babayan Z, Stapleton D, Joshi DD. Energy drinks and their adverse health effects: A systematic review of the current evidence. Postgraduate Medicine. 2015;127(3):308-322. 
Alsunni AA. Energy drink consumption: beneficial and adverse health effects. International Journal of Health Sciences (Qassim). 2015;9(4):468-474.

Blankson KL, Thompson AM, Ahrendt DM, Patrick V. Energy drinks: what teenagers (and their doctors) should know. Pediatrics in Review. 2013;34(2):55-62.

Coppinger T, Jeanes Y, Mitchell M, Reeves S. Beverage consumption and BMI of British schoolchildren aged 9-13 years. Public Health Nutrition. 2013;16(7):1244-1249.

Costa BM, Hayley A, Miller P. Young adolescents' perceptions, patterns, and contexts of energy drink use. A focus group study. Appetite. 2014;80:183-189.

Currie C, Zannoti C, Morgan A, Currie D, de Loze M, Roberts Ch, Samdal O, Smith ORF, Barnekow V, editors. Social determinants of health and well-being among young people. Health Behaviour in School-aged Children (HBSC) study: international report from the 2009/2010 survey. Health Policy for Children and Adolescents, No. 6. Copenhagen: WHO Regional Office for Europe; 2012.

Hamilton HA, Boak A, Ilie G, Mann RE. Energy drink consumption and associations with demographic characteristics, drug use and injury among adolescents. Canadian Journal of Public Health. 2013;104(7):e496-501.

Madarasová Gecková A, Dankulincová Z, editors. Národná správa o zdraví a so zdravím súvisiacom správani 11-, 13- a 15-ročných školákov. Bratislava: Kancelária Svetovej zdravotníckej organizácie na Slovensku; 2015. (in Slovak)

Marczinski CA, Fillmore MT. Energy drinks mixed with alcohol: what are the risks? Nutrition Reviews. 2014;72(S1):98-107.

Miyake ER, Marmorstein NR. Energy drink consumption and later alcohol use among early adolescents. Addictive Behaviors. 2015;43:60-65.

Nanney MS, MacLehose R, Kubik MY, Davey CS, Coombes B, Nelson TF. Recommended school policies are associated with student sugary drink and fruit and vegetable intake. Preventive Medicine. 2014;62:179-181.
Nowak D, Jasionowski A. Analysis of the consumption of caffeinated energy drinks among Polish adolescents. International Journal of Environmental Research and Public Health. 2015;12(7):7910-7921.

Pomeranz JL, Munsell CR, Harris JL. Energy drinks: an emerging public health hazard for youth. Journal of Public Health Policy. 2013;34(2):254-271.

Reid JL, Hammond D, McCrory C, Dubin JA, Leatherdale ST. Use of caffeinated energy drinks among secondary school students in Ontario: Prevalence and correlates of using energy drinks and mixing with alcohol. Canadian Journal of Public Health. 2015;106(3):e101-108.

Roberts Ch, Currie C, Samdal O, Currie D, Smith R, Maes L. Measuring the health behaviours of adolescents through cross-national survey research: recent developments in the Health Behaviour in School-aged Children (HBSC) study. Journal of Public Health. 2007;15:179-186.

Salamon M. Study: Alcohol-energy drink combo riskier than booze alone. USA Today; 2011 [cited 2016 Feb 8]. Available from: http://consumer.healthday.com/kids-health-information23/kids-and-alcohol-health-news-11/alcohol-energy-drinkcombo-riskier-than-booze-alone-study-says-651954.html Sanchis-Gomar F, Pareja-Galeano H, Cervellin G, Lippi G, Earnest CP. Energy drink overconsumption in adolescents: implications for arrhythmias and other cardiovascular events. Canadian Journal of Cardiology. 2015;31(5):572-575.

Schwartz DL, Gilstad-Hayden K, Carroll-Scott A, Grilo SA, McCaslin C, Schwartz M, Ickovics JR. Energy drinks and youth self-reported hyperactivity/inattention symptoms. Academic Pediatrics. 2015;15(3):297-304.

Simon M, Mosher J. Alcohol, energy drinks, and youth: A dangerous mix. San Rafael CA: Marin Institute; 2007 [cited 2016 Feb 8]. Available from: http://alcoholjustice.org/images/stories/EnergyDrinkReport.p df 